Journal of Finance Research

\title{
Research on the Performance Assessment Mechanism of Accurate Poverty Alleviation in Vocational Education
}

\section{Jinmei $\mathbf{W u}{ }^{*}$}

Guangxi Aquatic Animal Husbandry School, Nanning, Guangxi, 530021, China

\begin{tabular}{|c|c|}
\hline ARTICLE INFO & ABSTRACT \\
\hline Article history & \multirow{9}{*}{$\begin{array}{l}\text { Vocational education is an effective way to achieve accurate poverty al- } \\
\text { leviation and get rid of intergenerational poverty. Vocational education is } \\
\text { mainly to train skilled talents, not only to provide academic education for } \\
\text { the children of poor families, but also to use a skill to achieve employ- } \\
\text { ment. It is of great necessity to implement accurate poverty alleviation } \\
\text { in vocational education, and performance assessment is a very important } \\
\text { part of the accurate poverty alleviation work of vocational education. This } \\
\text { paper mainly analyzes the predicament of accurate poverty alleviation } \\
\text { in vocational education and the problems in the construction of perfor- } \\
\text { mance assessment system for accurate poverty alleviation in vocational } \\
\text { education, and puts forward measures to improve the accurate poverty } \\
\text { alleviation assessment system for vocational education and strengthen the } \\
\text { accurate of vocational education. }\end{array}$} \\
\hline Received: 28 June 2020 & \\
\hline Revised: 8 July 2020 & \\
\hline Accepted: 9 October 2020 & \\
\hline Published Online: 16 October 2020 & \\
\hline Keywords: & \\
\hline Vocational education & \\
\hline Accurate poverty alleviation & \\
\hline Performance assessment mechanism & \\
\hline
\end{tabular}

\section{Introduction}

$\mathrm{T}$ he 19th National Congress of the Communist Party of China proposed that targeted poverty alleviation should be one of the three major battles that must be achieved in building a well-off society. President Xi Jinping's instructions on accurate poverty alleviation provide a powerful ideological weapon for poverty alleviation. Vocational education plays an important role in the work of accurate poverty alleviation. Vocational education carries out the work of accurate poverty alleviation not only to enable students to master the corresponding skills, but also to improve the comprehensive level of students, so that children in poverty-stricken areas can receive vocational education with richer content, higher security and higher income. Vocational colleges need to continuously develop and strengthen themselves while doing the work of accurate poverty alleviation. In addition, the performance assessment mechanism is an important part of the vocational poverty alleviation, and it is very important to construct a complete accident poverty alleviation assessment system.

\footnotetext{
*Corresponding Author:

Jinmei $W u$,

born on December 23rd, 1972, a native of Pengzhou in Sichuan Province, Han nationality, who is an on-the-job master of accounting in Xiamen National Accounting Institute, a senior accountant and leader of accounting discipline in Guangxi Aquatic Animal Husbandry School, "Double-qualified" teacher;

Research direction: financial management;

Correspondence address: Guangxi Aquatic Animal Husbandry School, No. 7 Qingshan Road, Nanning, Guangxi, 530021, China; E-mail:726679550@qq.com.
} 


\section{The Significance of Implementing Accurate Poverty Alleviation in Vocational Education}

\subsection{Vocational Education Can Accurately Block the Intergenerational Transmission of Poverty}

The purpose of vocational education is to train technical and skilled talents for the society. The use of vocational education can greatly enhance employment and serve the people's livelihood $^{[1]}$. Vocational education plays an important role in accurately blocking the intergenerational transmission of poverty, mainly in the following aspects: First, vocational education bears a large part of the education of children in poor families. According to incomplete statistics, most of the students in vocational colleges come from rural families or families with financial difficulties in the city, from this point of view, it is very necessary to carry out accurate poverty alleviation in vocational education. Second, vocational education can enable students from poor families to acquire certain skills and skills, thereby promoting employment and improving family poverty to a certain extent. Third, vocational education can effectively help poor families to achieve high-quality employment. Under normal circumstances, vocational colleges often use school-enterprise cooperation, which is more secure in employment ${ }^{[2]}$.

\subsection{Vocational Education Can Accurately Help Poor People out of Poverty}

Vocational education not only carries out academic education, but also carries out various vocational trainings for the society, helping some technicians to improve themselves, and has the role that other education cannot replace. In the vocational education, the implementation of accurate poverty alleviation can help the poor to get rid of poverty, mainly in the following aspects: First, the poor can be implanted into the "gene" of poverty alleviation. Most of the poor people lack the corresponding information on getting rich, and their ideas are relatively backward, which is also the main cause of poverty, therefore, it is possible to provide the "gene" for poverty alleviation, so that it can gradually get rid of poverty in the mind, and thus help the poor to get rid of poverty. Currently, in many institutions, there is specialized training to enhance the confidence of getting rid of poverty. Second, vocational education can help poor people master the skills to get rid of poverty. The lack of knowledge and technology of the poor, lack of skills is an important factor in poverty, and vocational skills training in vocational colleges can greatly alleviate this problem. The third is to provide corresponding guidance and training for the production and operation of poor people. According to relevant research and research, most vocational colleges have conducted technical consultation and services for the poor ${ }^{[3]}$.

\subsection{Vocational Education Can Accurately Help Poverty-stricken Areas out of Poverty}

Vocational education plays an important role in the work of accurate poverty alleviation, which can help poverty-stricken areas to alleviate poverty to a certain extent, mainly in the following aspects: First, vocational education can provide skilled talents for poverty-stricken areas. Vocational education and local economic development are closely linked, and many skilled talents in poverty-stricken areas are mainly derived from vocational education. Second, vocational education can provide technical services for the development of poverty-stricken areas. Vocational colleges have professional faculty and technical personnel, which can provide favorable technical support for poverty alleviation in poverty-stricken areas. The third is to help poverty-stricken develop poverty alleviation projects. In poverty-stricken areas, they need to get rid of poverty as soon as possible. It is necessary to develop effective poverty alleviation projects as soon as possible, make full use of regional advantages, and develop poverty alleviation projects that promote economic development in the region.

\section{The Dilemma of Accurate Poverty Allevia- tion in Vocational Education}

\subsection{The Object Recognition Accuracy of Accu- rate Poverty Alleviation in Vocational Education Needs to Be Improved}

In the vocational education, the accurate poverty alleviation will inevitably lead to the problem of leaning the educational resources, so that poor students and their families can get more benefits in the accurate poverty alleviation. However, due to the large number of poor people in poverty-stricken areas, there are large differences between different families. Coupled with the lack of grassroots investigation work, there will be certain deviations in the identification of accurate poverty alleviation objects, and it is impossible to effectively put educational resources into the people who need the most help. Usually, most vocational colleges use written materials to judge the family's poverty. Students receive proof of poverty materials and pass the school's review, and the school subsidizes them. However, poverty alleviation offices in some areas require self-declared self-declaration, while poor people do not have a high level of understanding of the country's 
accurate poverty alleviation policy, and fail to report in time, thus causing omissions in the identification of poor people. There are also some poverty-stricken areas in poverty-stricken areas that need to be upgraded. In this case, some poor students will not be certified due to external factors.

\subsection{The Accurate Poverty Alleviation Mechanism in Vocational Education Needs to Be Improved}

The accurate poverty alleviation work of vocational education involves a wide range. Not only do the institutions themselves need to do a good job in accurate poverty alleviation, but also the institutions and relevant government departments need to do a good job of communication and coordination. However, from the development of accurate poverty alleviation work in Chinese vocational colleges, the accurate poverty alleviation mechanism of vocational education still needs to be improved, and the accurate poverty alleviation work of vocational education in some areas needs to be improved. In addition, vocational education and accurate poverty alleviation belong to different departments, so that colleges and universities will have greater difficulties in carrying out accurate poverty alleviation. In order to carry out accurate poverty alleviation projects, institutions need to report to the local education departments and poverty alleviation offices separately, which has caused the institutions to be less efficient in carrying out accurate poverty alleviation and it is difficult to carry out their work effectively. Moreover, due to the different degrees of economic development in different regions, the types of vocational colleges in different regions are also different. Under normal circumstances, different types of institutions belong to different government departments, which also pose certain difficulties for the development of accurate poverty alleviation work. Therefore, it is very important to improve the accurate poverty alleviation mechanism of vocational education ${ }^{[4]}$.

\subsection{The Measures of Accurate Poverty Alleviation in Vocational Education Needs to Be Improved}

Since the 19th National Congress put forward the "accurate poverty alleviation" policy, all regions in China have gradually carried out accurate poverty alleviation work. The state has also issued a number of documents and policies, and initially formed an accurate poverty alleviation mechanism, which provides a solid theoretical basis for the development of accurate poverty alleviation work in various regions. Under this circumstance, the accurate poverty alleviation work of vocational education is also being carried out smoothly. At present, a certain mode has been formed, and vocational education has also promoted the development of poverty-stricken areas and poor people to a large extent. However, there are still certain problems in the current accurate poverty alleviation work in vocational education. There are mainly two aspects. On one hand, there is not much integration between the development of poverty alleviation work in vocational colleges and the development of regional economy, which makes it difficult to implement many specific measures to improve poverty. On the other hand, vocational education and poverty alleviation workers do not fully understand the actual situation of poverty alleviation areas, and the training content that has been developed is inconsistent with the actual situation, and it is difficult to exert the value of its application.

\subsection{Vocational Education Poverty Alleviation De- velopment Is out of Touch with the Needs of the Labor Market}

Vocational education is also a form of Chinese education, and the corresponding ones will be affected by the test-oriented education. Many vocational colleges have not kept pace with the times in many aspects, which made it difficult for the talents trained to meet the actual needs of society, which has also greatly restricted the development of vocational education in China. In recent years, vocational colleges have been continuously reforming and have made certain progress. However, in some underdeveloped areas, due to lack of resources and the backwardness of teachers, the development of vocational education and social needs are out of touch. Judging from the current development of vocational education poverty alleviation work, poor market areas have not yet established a sound market feedback mechanism, which is less sensitive to the market and it is difficult to guarantee the effective employment of students. In addition, the communication between the institutions and the enterprises in the process of carrying out accurate poverty alleviation needs to be further improved, so that the employment situation of students is affected accordingly.

\section{The Construction of Performance Assess- ment System for Accurate Poverty Alleviation in Vocational Education}

\subsection{The Principles for the Construction of Perfor- mance Assessment System for Accurate Poverty Alleviation in Vocational Education}

As an important part of the accurate poverty alleviation work, the performance assessment system has a strong 
promotion effect on the entire accurate poverty alleviation work. In the construction of the vocational education accurate poverty alleviation performance assessment system, the following principles need to be followed.

\subsubsection{The Principle of Participation}

The construction of performance assessment indicator system not only needs to consider whether the college has reached the corresponding goals, but also needs to consider the main feelings of the poverty alleviation target, earnestly do a good job in poverty alleviation work, ensure the local adaptability of poverty alleviation work, and avoid the situation of poverty alleviation. As the main beneficiary of accurate poverty alleviation, the overall poverty alleviation is very important. It is necessary to focus on the feelings of poverty alleviation, focus on improving the problems raised by them, and promote the effective development of accurate poverty alleviation. It is very necessary to strengthen the exchanges and interactions between institutions and poverty alleviation objects. In the performance assessment system, the satisfaction of poverty alleviation targets should be included.

\subsubsection{The Principle of Integrity}

As a comprehensive project, poverty alleviation work involves more content and is related to all aspects of poverty alleviation. Therefore, when formulating the performance assessment system, there are more contents to be covered.

\subsubsection{The Principle of Measurability}

In the formulation of the performance assessment system, all performance assessment indicators can be expressed by specific indicators, and the corresponding data can be used for detection and statistics. When using the general performance assessment indicators, it is necessary to combine the actual situation of the region and provide corresponding data support for the accurate poverty alleviation work in the region.

\subsubsection{The Principle of Systematicness}

As the external environment changes, the performance assessment will also change accordingly. To this end, in the performance assessment, it is necessary to fully consider the external situation changes and adjust the performance assessment indicators accordingly.

\subsection{The Methods of Constructing Performance Assessment System for Accurate Poverty Allevia- tion in Vocational Education}

The general construction methods of the performance assessment system are the methods of cost-effective, analytic hierarchy process, comprehensive scoring, artificial neural network, etc. There are many methods for constructing the performance assessment system. Different methods have different advantages and disadvantages. When using these methods, you need to choose the most suitable construction method according to the actual situation $^{[5]}$. Different scholars will adapt to different performance system construction methods in the research process, and use statistical data to give corresponding data analysis. Based on the comprehensive performance assessment methods, this paper puts forward a performance assessment indicator system including the subjects, objectives, means and environment of accurate poverty alleviation. The subject of accurate poverty alleviation is the resource problem. In terms of accurate poverty alleviation in vocational education, the subjects of accurate poverty alleviation can be schools, governments and corresponding social welfare organizations, which involve various issues such as financial input and manpower input. There is no uniform standard for the definition of poverty alleviation goals, either in terms of survival or economic.

\subsection{The Application of Performance Assessment System for Accurate Poverty Alleviation in Voca- tional Education}

The application of the performance assessment indicator system in the accurate poverty alleviation of vocational education can measure the actual effect of accurate poverty alleviation in vocational colleges to a certain extent, fully reflect the problems in the accurate poverty alleviation of vocational education, and take corresponding improvement measures to improve the accurate of vocational education and poverty alleviation.

\section{Existing Problems in the Performance As- sessment System for Accurate Poverty Allevi- ation in Vocational Education}

Judging from the development of the accurate assessment system for vocational education, the theoretical research level of accurate poverty alleviation performance assessment has improved, but there are still certain problems in the performance assessment system.

\subsection{The Construction of the Indicator System Needs to Be Scientific}

After relevant researches, the current accurate poverty alleviation in vocational education performance assessment system gradually presents diversified development, but there are still some problems in the performance assess- 
ment system for accurate poverty alleviation in vocational education, mainly reflected in the following aspects ${ }^{[6]}$. First of all, the construction of the indicator system needs to be further improved. The purpose of accurate poverty alleviation is to improve the poverty situation in poverty-stricken areas and to get rid of poverty in time. As the main beneficiary of accurate poverty alleviation, poverty alleviation is also a direct judge of accurate poverty alleviation. However, from the current vocational education accurate poverty alleviation performance assessment system, Most of them judge the effect and situation of accurate poverty alleviation from a macro perspective, but rarely touch the subjective view and concept of poverty alleviation objects. This leads to the lack of comprehensiveness of the performance assessment system and the existence of certain one-sidedness. In addition, when constructing the performance assessment system, the participation of poverty alleviation targets is often lacking, and whether the life of the poverty alleviation objects has been effectively improved is the most direct judgment on whether the poverty alleviation work is effective. This factor needs to be added to performance assessment indicators to ensure the comprehensiveness and scientificity of the performance assessment system. Secondly, it is necessary to improve the reliability of the performance assessment system. Although the theoretical indicators are more feasible in the accurate performance assessment of vocational education, there is still certain feasibility in practical application, and the operability needs to be improved.

\subsection{The Methods of Constructing Indicator Sys- tem Need to Be Diversified}

Although there are many methods that can be used in the construction of the indicator system, there are still some problems in practical applications, and it is necessary to improve the diversification of the construction methods. Performance assessment needs to make more scientific and accurate judgments on accurate poverty alleviation through quantitative and qualitative comparative analysis. The usual method used in the construction of current performance assessment indicators is the "input-output" comparison method. Although this method is more convenient and intuitive, there are still major difficulties in determining the input-output problem, and it is necessary to further determine the accuracy of the performance assessment. In addition, some scholars also use statistical methods to improve the assessment indicator system. However, more statistical methods can be used in the construction of the indicator system to improve the comprehensiveness and comprehensiveness of performance assessment indicators $^{[7]}$.

\subsection{The Construction Results of the Indicator As- sessment System Need to Be Further Implemented}

The performance assessment indicator system is designed to better implement the accurate poverty alleviation mechanism, better promote the development of poverty-stricken areas, improve the lives of the poor, and use performance assessment mechanisms to identify problems in the accurate poverty alleviation work and take corresponding recommendations. However, it is found that the implementation of the performance assessment indicator system is insufficient in the current performance assessment indicator system. First of all, it is found from the existing research that the number of applications of the assessment indicator system is very low, but it is obviously insufficient in practical application. Moreover, the application of most assessment indicator systems is applied in local areas, and there are certain limitations. The comparability of local assessments is poor. It is difficult to effectively analyze the assessment results, and the quality of the assessment system of indicators is further improved.

\section{Ways to Strengthen the Accurate Poverty Alleviation in Vocational Education}

\subsection{Improve the Classification and Identification Methods for Objects in Poverty}

In the accurate poverty alleviation work, we must first solve the problem of accurate identification of accurate poverty alleviation objects. The key points and difficulties of accurate poverty alleviation are on accurate issues. The Party Central Committee has put forward the "six accurate" requirements for accurate poverty alleviation work. The first requirement is to ensure the accuracy of poverty alleviation objects. As an effective channel for carrying out accurate poverty alleviation work, vocational education needs to further strengthen the work of accurate poverty alleviation and improve the classification and identification methods of poverty alleviation objects. Sound accurate identification can start from the following aspects: First, it is necessary to strengthen the comprehensive and comprehensive investigation of poverty alleviation targets. In the identification work of poor people and poor families, it is necessary to break the traditional limitations, and do a good job in field investigation to ensure the authenticity of the investigation results. The grassroots departments should set up corresponding investigation and identification teams to strengthen the field investigation work. There is no personal feeling in the investigation process, and it is necessary to conduct corresponding in- 
vestigations according to the situation on the ground. Second, after understanding the actual situation of the poor students, it is necessary to further understand the causes of poverty, poverty alleviation and other aspects, and then take corresponding measures. On the basis of government identification, vocational colleges should further improve the identification methods of poor students and provide an effective way for students who need to improve their poverty alleviation ${ }^{[8]}$.

\subsection{Perfect the System Construction of Accurate Poverty Alleviation in Vocational Education}

Vocational education has achieved certain results in the work of accurate poverty alleviation. However, it is still necessary to further improve the system of accurate education for poverty alleviation in vocational education, and provide a better external environment for the development of accurate education for vocational education.

The improvement of the system is more utilized to carry out accurate poverty alleviation work. At this stage, it is very important to improve the system of accurate education for poverty alleviation in vocational education. Colleges and universities need to establish sound and accurate poverty alleviation mechanisms and norms. Accurate poverty alleviation is a comprehensive and comprehensive project. It involves more content and is often complicated. It involves not only the skills education of students, but also the relationship between various social stakeholders. To improve the accurate education of vocational education, we need to start from the following two aspects. First, the state should strengthen the construction of laws and regulations on accurate poverty alleviation in vocational education, make up for the lack of law in accurate poverty alleviation, and focus on the positioning of vocational education in accurate poverty alleviation. Clarify the rights and obligations of vocational education in the precise poverty alleviation. Second, it is necessary to strengthen the guidance to local governments, assist local governments to establish a precise poverty alleviation mechanism for vocational education, and take the initiative to undertake their precise poverty alleviation work ${ }^{[9]}$.

\subsection{Improve Vocational Educational and Training Systems in Poverty-stricken Areas}

Most of the poverty-stricken areas have similar characteristics. The economic development level of these areas is relatively backward, and the educational mechanism needs to be improved. Although the education system in some areas has a certain level of hierarchy, it is subject to external factors, and there is still room for improve- ment in the quality of teaching. The ability to serve the society is also greatly limited. To carry out accurate poverty alleviation work in vocational education, it is necessary to establish a sound vocational education and training system to further enhance the skill level of vocational education. Through a multi-level, three-dimensional education system, it can improve the education level of vocational colleges to a certain extent. When building a vocational education and training system in poverty-stricken areas. Firstly, we must ensure that there is consensus and agreement between the institutions and local governments, and we all agree with the development of vocational education and training. Secondly, in view of the actual situation of the educated, targeted teaching should be carried out to improve the skill level of the learners. Thirdly, the local government should also play its full role, do a good job of optimizing the allocation of resources, and combine the educational resources of the institutions with the social education to improve the skills of students. Finally, local governments also need to strengthen the promotion and promotion of accurate education in poverty alleviation in vocational education, so that more people can realize the significance and importance of accurate poverty alleviation.

\subsection{Strengthen the Link between Vocational Edu- cation and the Market}

The key to carrying out accurate poverty alleviation in vocational education is that vocational education is mainly to train skilled talents, which can greatly promote the employment of students, therefore, in the process of carrying out accurate poverty alleviation, vocational education needs to strengthen the connection between vocational education and the market, so that the institutions are more sensitive to the employment direction, and thus increase the employment rate of the school. In the process of carrying out accurate poverty alleviation, schools should focus on the changes in the market, keep abreast of market dynamics, and do appropriate education and training ${ }^{[10]}$.

\section{Conclusion}

The 19th National Congress of the Communist Party of China put forward that poverty alleviation is the key task of China's current poverty alleviation. It is very necessary to carry out accurate poverty alleviation in vocational education. The development of accurate poverty alleviation can effectively improve the problem. As an important basis for measuring accurate poverty alleviation, performance assessment mechanism is also very important to build a perfect performance assessment mechanism. 


\section{References}

[1] Gang Wang. Research on the Mode and Policy Driven Mechanism of Accurate Poverty Alleviation in Vocational Education[J]. Journal of Continuing Education, 2017:26. (in Chinese)

[2] Yan Li. The Practical Difficulties and Countermeasures of the Performance Evaluation Mechanism for Precision Poverty Alleviation[J]. Journal of Qinghai Social Sciences,2016(3). (in Chinese)

[3] Guanghui Mo. Industrial Poverty Alleviation Practice and Path Optimization under the Perspective of Accurate Poverty Alleviation_-A Series of Researches on Precision Poverty Alleviation Performance Improvement Mechanism[J]. Journal of Yunnan University (Social Science Edition),2017(1). (in Chinese)

[4] Zhihua Meng, Xiaodong Li. Third-party Evaluation of Precision Poverty Alleviation Performance: Theoretical Traceability, Mechanism of Action and Optimization Path[J]. Contemporary Economic Management, 2018(3):46-52. (in Chinese)

[5] Ying Dai. Construction and Application of Indicator System for Performance Evaluation of Precision Poverty Alleviation[J]. Labor Security World,2017(14). (in Chinese)

[6] Haijun Xia, Xiaqing Wei, Guowei Qin. Introduction and Promotion Strategy of Third-party Evaluation in Poverty Alleviation: A Third-party Assessment of Colleges and Universities in Anhui Province in 2016[J]. Research on Development, 2017(06):84-88. (in Chinese)

[7] Guangjun Guo, Ying Shao, Binbin Deng. Research on Accelerating the Countermeasures of Poverty Alleviation and Poverty Alleviation in Vocational Education[J]. Education and Vocation,2017(10). (in Chinese)

[8] Xiaohong Peng. The basis, dilemma and outlet of vocational education for poverty alleviation[J]. Education and Vocation, 2017:21. (in Chinese)

[9] Tingyun Deng, Zhiming Tang. Analysis of the Problem of Accurate Poverty Alleviation in Non-degree Vocational Education in the Depressed AreasTaking the Rocky Desertification Area of YunnanGuangxi-Guizhou as an Example[J]. Vocational and Technical Education, 2016,37(22). (in Chinese)

[10] Dexin Xie. The Theoretical Basis, Meaning Interpretation and Functional Orientation of Precision Education for Vocational Education[J]. Vocational \& Technical Education Forum,2018. (in Chinese) 